\title{
THE Right TO KNOW: WHAT, WHEN AND FOR HOW LONG. APPRAISAL AND SELECTION IN THE INFORMATION AGE?
}

\author{
CHARLES JEURGENS*
}

\section{INTRODUCTION}

When people think of archives they often think of old papers that may still have some historical value, but without much relevance for current affairs. When we exchange the term 'archive' for the word 'information', the meaning changes immediately. Information is hot, societal and politically relevant. However, when government institutions use the word 'information', they actually most of the time mean records or archives. According to Elayne Coakes and Steve Clark, a record is defined as "process-bound information because a record is generated by work processes, structured and recorded by these work processes in order to be retrieved from the context of those work processes" . A record has four elements: recorded (physically), it contains information (content), it is the outcome of the process in which it was created (context), and it has certain forms or manifestations (structure). Contextual information is necessary for defining a document as a record. Records are documentation of transactions and preserved for evidential, historical and cultural purposes. As archives are by definition process-bound information, they form the administrative records of the activities and deeds a government has carried out.

Information is the fuel that runs state institutions. Government institutions use information to shape and to implement policies, but at the same time they are significant producers of information. However, official information is more than just the fuel to keep the engine of policy making and implementation processes running. It also serves a number of important social values. After all, official information is of fundamental significance for civic participation, for institutions to be able to be accountable, for citizens to seek out the truth (finding evidence and justice) and for them to

DOI: 10.2478/wrlae-2013-0050

*Professor of Archival Sciences, Leiden University/NationaalArchief, Netherlands, k.j.p.f.m.jeurgens@hum.leidenuniv.nl

${ }^{1}$ Elayne Coakes and Steve Clark (eds), Encyclopedia of communities of practice in Information and Knowledge Management Records (2006). 
learn their own history. Professional information management ensures that all these roles and objectives of information will be addressed properly. Information that may be there but which is hardly accessible is without any meaning. Information that is destroyed accidentally or on purpose but is still sought may cause serious problems for the government, while information that should have been destroyed but is wrongfully kept may harm the privacy of people. Solid information management means properly balancing all these different interests in a transparent manner.

Because of the overwhelming surplus of information that is produced and collected nowadays, professional information management, which takes all these divergent interests into account in an integrated way from the start, is more urgent than ever. It is not so easy to quantify the production of information. Lyman and Varian calculated that in 2002 about 5 exabytes ( 5 billion gigabytes) of new data was being stored worldwide. According to the International Data Corporation (IDC), the amount of created and duplicated data exceeded 800 exabytes in $2007^{2}$.

\section{APPRAISAl AND SELECTION}

Appraisal and selection are directly connected to accountability. Appraisal and selection determine whether citizens will be able to access government records. Appraisal is the process of evaluation and determination of whether records have permanent value or may be destroyed after a certain time, specified for each category by a retention schedule. Appraisal is tightly coupled with selection, which is the administrative process of adding disposition decisions to records in a way that they can be identified. Disposition is the actual destruction of records or their safeguarding, most often by transferring them to an archival repository.

The Dutch Archives Act requires that government agencies keep their records in a proper, organized and accessible way. That same act prescribes that government agencies must have a disposition of retention schedules to distinguish between records that should be kept for a certain period of time and records of enduring value which should be transferred to an archival repository. Disposition of government records which is not based on stipulated retention schedules is unlawful. Transfer guarantees public access to records, which under the most recent wording of the Archives Act of 1995 is set at 20 years after the records were created. The Archives Act, together with the Freedom of Information Act, guarantees public access to governmental information. The Freedom of Information Act applies to government information that is not transferred to an archives repository, while the Archives Act applies to government information that is transferred. The outcome of appraisal and selection of records determines whether government information ever becomes public or is destroyed after a certain period of time. This makes appraisal and selection highly relevant, not only for the right to know but especially for the ability to know about government activities.

\footnotetext{
${ }^{2}$ Geert-Jan van Bussel, Archiving should be just like an Apple ${ }^{T M}$ ' en acht andere, nuttige (?) stellingen (Inaugural lecture HVA 2012).
} 
Until well into the 1980 s, appraisal and selection was conducted only at the document level. Appraisal and selection usually concerned documents that had been created many years previously and were no longer in daily use by administration. As in most countries, creation of archives and appraisal and selection in the Netherlands were for the most part two very different things. Records managers were responsible for the management of records in line with the interests of the creating agency. For the daily management of these records, different tools were available (registers, indexes, filing procedures etc.). When records became outdated and were no longer frequently used by the creating agency, they were often transferred to basements or lofts, awaiting definitive appraisal and selection at a later time. In the Netherlands, the Archives Law of 1962 required the transfer of government records not marked for destruction to an archival repository 50 years after their creation. As said before, this act of transfer marks the starting point of a new statutory regime: the documents become public.

Appraisal and the subsequent selection of records usually took place many years after they were put aside by the agencies that had produced them. As long as the amount of documents is limited, it is possible to carry out appraisal and selection in this way, although most would agree that it has little in common with professional information management. Appraisal and selection were not integrated into the information management processes of government institutions, and was not at all relevant to the interests of the primary processes of these record-creating institutions. No wonder that the general attitude of government agencies towards archivists was: come and pick out the documents you need, but don't bother me too much with cultural heritage matters in my primary processes. Appraisal and selection was regarded as relevant for creating a 'historical memory', but without much significance for the creating agencies, and apparently without much meaning for the right of citizens to have access to these files.

In the late 1980s and early 1990s attitudes towards appraisal and selection changed. The massive increase of records resulting from an exploding bureaucracy after World War II combined with the commitment to transfer - and make public - all archived documents after twenty years (instead of the standard applied then of fifty years) to an archive repository on the basis of a future amendment to the Dutch Archive Act (which became operative in 1995) led to the realisation that the existing methods of appraisal and selection at the document level were no longer tenable. Under the new Archives Act, records-creating agencies were suddenly obliged to examine records created before 1975 to conform to the new legal requirement to transfer and make public records of enduring value 20 years after their creation. There was an urgent need to develop a new approach to appraisal and selection, which led to a new method of macro-selection. Instead of individual documents being appraised on their own, the functions or activities that were performed by governmental organisations were appraised. This method is currently used by all records-creating agencies of 
central, provincial and local government in the Netherlands ${ }^{3}$. It should be mentioned that macro-appraisal was not invented by the Dutch, but was a development that took place in many countries ${ }^{4}$.

This method of macro-appraisal is based on the principle that all administrative records that emanate from a function will follow the appraisal of that function. Without going into details here, the method was, however, equally incapable of preventing the continual buildup of backlogs in processing archives. The most significant reason for this lied in the fact that it was by no means easy to produce effective descriptions of governmental functions, and more importantly because archiving in actual practice was frequently not organised in accordance with the developed model of functions, which turned the identification and linking of documents to a particular function into a difficult and laborious operation. Furthermore, the different types of descriptions of functions, varying from completely abstract to highly detailed accounts, together with the abundance of functions applied in the selection procedure, made these tools susceptible to high maintenance and their application quite complicated ${ }^{5}$.

Appraisal may have become much simpler, and particularly much faster, in comparison with the times when documents rather than functions were the objects of appraisal, but the big bottleneck occurs in the implementation and application of the selection by these retention schedules that were created via this method. Selection has predominantly become a problem of identification. This is not only the case in the Netherlands. In 2005, Brian P. N. Beaven, who since 1989 has been employed by the 'Government Records Appraisal and Disposition Program' of the Library and Archives Canada, published an article with the loaded title 'But am I getting my records?' ${ }^{\prime}$. In this article, he focuses attention to the problem of macro-appraisal: how can theory and methodology be converted into the effective selection of documents? Inspired by this question, I began exploratory research in the Netherlands to find out whether the files and documents that were selected and transferred to the National Archives by the macro-appraisal method were consistent with the outcome of the process of appraisal that resulted in retention schedules. The conclusion of this exploratory research confirmed the notion mentioned earlier that appraisal and selection are indeed two very different things. Alarming are the findings that the transferred documents and files only partly mirrored what,

\footnotetext{
3 Agnes Jonker, 'Macroappraisal in the Netherlands. The first ten years, 1991-2001 and beyond' (2005) 5 Archival Science 203.

4 Terry Cook, 'What is past is prologue. A history of archival ideas since 1898 and the future paradigm shift' (1996) 43 Archivaria 17.

${ }^{5}$ See for an overview of the functions of the central government in the Netherlands the so called 'Handelingenbank', <http://www.handelingenbank.info > accessed 15 August 2014.

${ }^{6}$ Brian P.N. Beaven, 'But am I getting my records? Squaring the Circle with Terms and Conditions Expressed in Relation to Function and Activity' (2005) 5 Archival Science 315. Beaven took this title from the essential question asked of the managers of the Government Records Appraisal and Disposition Program by Ian Wilson, Librarian and Archivist of Canada. Elsewhere he postulated "It is not enough for us simply to do an appraisal and issue our authority for transfer or disposal, we need equally to ensure that the result is what we intended. Our commitment is not to a process but to the integrity of the official record. Are we certain that we are accomplishing what we set out to accomplish?" (ibid 315).
} 
according to retention schedules, should have been transferred ${ }^{7}$. The quality and effectiveness of the selection is, at least based on this tentative research, inadequate. This is all the more distressing because the Dutch government devotes a lot of money and energy to the steering mechanisms of archives selection by way of drawing up and determining retention schedules, but seems to care less about the selection itself. This strikes at the core of citizens' right to know, because in the end the only important matter is whether the relevant documents are there. The retention schedules are the result of careful, detailed and often prolonged research and negotiation procedures with checks and balances in which the creating agency, archivists, historians and until now even the Council for Culture are involved, and citizens have the opportunity to have an opportunity to comment on the draft versions of the retention schedules; however, once the retention schedules are determined, published and become tools for selection, no one seems to be interested in the way they are used to perform a real selection. In fact, only the understaffed Archives Inspectorate (today bearing the unfortunate name of the Heritage Inspectorate) monitors the selection process.

All this means that, even without the fundamental changes that are taking place nowadays with respect to the creation and management of information, we should rethink our methods of appraisal and selection. Information management is changing in a fundamental manner as a consequence of a rapid succession of intertwined developments which are largely technological in nature (digitisation, internet and social media), but which are also tightly coupled with social developments, like changing relationships between citizens and governments, or the widely recognized and accepted need to be able to access relevant information at any time of the day. The impact on information management from these changes is immense. How to deal with these new developments from an archival perspective? What are the consequences for appraisal and selection of government information?

\section{REMEMBERING AND FORGETTING}

Not so long ago, the Dutch businessman and founder of a famous Dutch chain of private schools, Eric Luzac, went to court to demand the removal of several newspaper articles from the on-line archive of one of the Netherland's most recognized morning papers, De Volkskrant. In these articles, Mr. Luzac was portrayed as an unreliable businessman, and since their publication a few years earlier it had become almost impossible for him to get a loan from banks to start a new business. Mr. Luzac wanted to prevent further damage resulting from the dominant presence of this information on the Internet. The judge, however, was very clear in his verdict: removal of these articles from the on-line archive would harm the

\footnotetext{
${ }^{7}$ Charles Jeurgens, 'Maken archivarissen geschiedenis? Waardering en selectie onder de loep' (2010) 114 Archievenblad 42.
} 
integrity and completeness of the newspaper's archives, and this would open the door to rewriting history. The judge recognized that the Internet could be very inconvenient for people who do not want to be confronted with negative things from their past, but creating an archive filled only with positive news was, of course, out of the question ${ }^{8}$.

People are becoming more and more aware of the privacy drawbacks of the Internet, which lends support to the idea of a new phenomenon described by Viktor Mayer-Schönberger in his book Delete. The Virtue of Forgetting in the Digital Age. In this book, the author depicts a fundamental change taking place in our relationship with information. Since the beginning of time, forgetting has been the norm and remembering the exception. In the analogue age, effective remembering was complex, timeconsuming and costly. Remembering always remained a bit harder than forgetting. However, according to Mayer-Schönberger digital techniques mean that remembering instead of forgetting will become the norm ${ }^{9}$. The implications are far-reaching. Individuals like Mr. Luzac are hardly able to get rid of their past. One mistake committed in the past may haunt people for years and even decades. The Internet will remember people with precision, and as a consequence the past will always be present. We may wonder what kind of past we get by the incapability of forgetting. Once we have a perfect memory, we will remain lost in the details of our past, like in the case of a 41-year old woman from California who was without the biological gift of forgetting. She became caught up in her memories, unable to leave the past behind and incapable of abstract thoughts ${ }^{10}$. Will that be the future of our history?

\section{THE FATE OF DIGITAL INFORMATION}

We may wonder what the impact of the digital information society will be on the archival functions of appraisal and selection. Will appraisal and selection become obsolete, and old-fashioned functions rendered superfluous by digital techniques? While we share the views of MayerSchönberger, we should at least question the current direction of appraisal and selection, which remains based on the idea of safeguarding the memory of institutions and individuals. Appraisal and selection tries to identify the information worthy of being passed on. In the view of Mayer-Schönberger, this is a waste of energy in the digital world, in which we ought rather to worry about the necessity of deleting information.

\footnotetext{
${ }^{8}$ Eric Jan Luzac v. Omroepvereniging HA-ZA 09-2775 (2010) and Eric Jan Luzac v. De Volkskrant HA-ZA 09-2776 (2010). The 'right to be forgotten' has been put on the agenda by politicians and by scholars. After this paper was written for the conference in Wroclaw in 2011, the 'right to be forgotten' received a lot of attention within the European Union. The European Commission has disclosed a draft of a European Data Protection, which includes the right to be forgotten in Article 17 I. In May 2014 the European Union Court of Justice ruled that Google can be required to remove data that is "inadequate, irrelevant or no longer relevant, or excessive in relation to the purposes for which they were processed and in the light of the time that has elapsed".

${ }^{9}$ Viktor Mayer-Schönberger, Delete. The virtue of Forgetting in the Digital Age (Princeton University Press 2009).

10 ibid 12-13.
} 
But is it really as simple as this? Of course, the Internet often appears to be an infinite and sometimes uncomfortable memory that shows up at awkward moments, but the picture that Mayer-Schönberger sketches is just part of the story, and likely a small part of it at that. Although there is an unimaginable amount of data on the Internet, it is at the same time problematic to value the reliability, authenticity and completeness of the available information ${ }^{11}$. Furthermore, we should not forget that there is much digital information which is not accessible at all via the Internet. What is the fate of that information? And how do we want to deal with that information? We are all aware of alarming reports on information loss in a digital world. The general view, at least in the Netherlands, is that governmental agencies are not in control with respect to their information management. Documents get lost, are untraceable or cannot be understood because of missing information that would provide context. At the same time, information is quite often kept much too long, in contradiction to the rules, or becomes public unintentionally ${ }^{12}$. The Dutch National Audit Office recently expressed its concern about the problematic quality of information management by Dutch governmental agencies. Because of this, the rights of citizens and the quality of government are at risk. One of the very problematic issues these investigations always mention is the function of appraisal and selection of records. The Dutch National Audit Office appreciates that appraisal and selection is a difficult issue ${ }^{13}$. For decades, it concluded, we have struggled with this issue without finding a sustainable solution. In spite of the use of innovative methods, such as the introduction of the aforementioned functional approach in the 1990's, we still are confronted with enormous backlogs in appraisal, selection and processing of paper archives. Between 400 and 800 kilometres of paper archives created by governmental agencies in the period between 1975 and 2005 are waiting for appraisal, selection and processing. The situation with respect to digital archives born in that same era is even worse. The analogue and digital archives created in that period are completely out of our control, and a lot of information has been lost in an uncontrolled manner. This means that citizens can have no certitude at all about their right to know. The information may be there but inaccessible, or it may be deleted - nobody knows.

\footnotetext{
11 'The data deluge' [2010] The Economist .

${ }^{12}$ Rijksarchiefinspectie, Een dementerende overheid? De risico's van digitaal beheer van verantwoordingsinformatie bij de centrale overheid (2005).

13 In dienst van de democratie. Het rapport van de Commissie Toekomst Overheidscommunicatie (2001); Eenmalige Commissie ICT en Overheid, Burger en overheid in de informatiesamenleving \& De Noodzaak van institutionele innovatie (2001); Rijksarchiefinspectie, Een dementerende overheid? De risico's van digitaal beheer van verantwoordingsinformatie bij de centrale overheid (2005); Raad voor Cultuur, Het Tekort van het Teveel. Over de rijksverantwoordelijkheid voor cultureel erfgoed (2005); Informatie op Orde. Kabinetsvisie op vindbare en toegankelijke overheidsinformatie (2006); Raad voor het Openbaar Bestuur en Raad voor Cultuur, Informatie grondstof met toekomstwaarde (2008); Algemene Rekenkamer, Informatiehuishouding van het Rijk (2010) 15.
} 


\section{Appraisal AND Selection In The Digital ERA}

Let us return to the basics of appraisal and selection. Appraisal is a multifaceted process in which three main interests play a role: the operational need for information, regulatory requirements and historical interest. Providing access to information fosters a culture of accountability. Archivists should be the watchdogs of that culture, in which they serve not only short-term but preferably long-term interests. Since archivists are professionally engaged in the issue of appraisal and selection, there has never been an extensive discussion on the relevance of it. However, as mentioned earlier, some doubt has arisen about the necessity of appraisal and selection, caused by those who believe that there are no longer any technical limitations in the storage and retention of information. There are, however, important reasons why appraisal and selection are still necessary in our digital era. Some of these are fundamental, while others are more instrumental. Fundamental is the fact that appraisal creates value. Eric Ketelaar addresses the importance of forgetting in a different context than Mayer-Schönberger does. According to Ketelaar, cultural memory is created through forgetting. Societies cannot remember everything, and the sole act of appraisal and selection adds value. That said, there are also more instrumental reasons to appraise and select in a digital environment. Although it is not easy to compare the costs of long-term preservation of digital records with the costs of maintaining analogue documents, all available models do agree on one thing: the costs of administering digital archives are probably underestimated rather than overestimated, and storage of digital information is not less expensive than storage of paper materials ${ }^{14}$. A more fundamental argument for the continued importance of selection in the digital environment is the disproportional efforts needed to make and to keep digital archives accessible for future users. Some of the metadata crucial for accessibility can (and will) be added automatically by digital systems, but the human factor will continue to be important, and labour costs need to be taken into consideration. Metadata are the keys for finding the needles of information in the haystacks of data. To keep records without appropriate metadata make these records meaningless. A culture of accountability only can flourish if information can be found in its context of creation. The explosive growth of the quantity of documentary information compared to the efforts necessary to make this information accessible leads to the conclusion that selection in a digital environment is a precondition for accessibility. There is no reason, even disregarding the legal obligations (especially connected to interests of privacy) to destroy certain kinds of information, not to take

\footnotetext{
14 Recently, two important advisory bodies for the Dutch government (the Public Administration Council and the Council for Culture) referred to the high costs of administering digital information in a joint report: Informatie: Grondstof met Toekomstwaarde (Information: Raw Material Worth Investing In. The Hague 2008). The report cites Jim Gray, Microsoft's Director of Research, who stated that the costs of accessing, administering and maintaining 1 terabyte amounts to roughly 300,000 USD per year.
} 
appraisal and selection just as seriously in a digital environment as in the world of tangible media.

\section{CRISIS IN APPRAisAl AND SElECTION}

I do not feel that it is an exaggeration to assert that appraisal and selection are in crisis. Doubts about the necessity of selection in a digital environment on the one hand, and the apparent incapability of records managers and archivists to deal with appraisal and selection in the paper world on the other, are a bad starting point for a promising contribution by archivists to sound information-management in the digital world. From a theoretical point of view, however, we know what we need to do.

Appraisal should be conducted immediately at the moment records are created $^{15}$. Reality, alas, is different. Appraisal and selection are organized to an excessive degree in retrospect. If we continue to organize appraisal and selection by looking through the rear-view mirror, we will lose our credibility in the digital world. In the digital age, records managers and archivists are forced to practice a more rigorous and proactive approach, and should apply appraisal at - or even better before - the moment of creation of information artefacts. This makes archivists nervous because the distance in time they were used to made it easier to assess records. In a digital world, this is no longer an option. Appraisal and selection is needed at an early stage to guarantee proper records management. "Proper" means that these records can be accessed in both the near and distant future in a way that guarantees authenticity and reliability. Paper documents can still be read many decades or even centuries after creation, but digital records become obsolete within a few years, and without appropriate management and facilities they will be lost after some time because of a lack of suitable software or hardware. In other words: the act of appraisal and selection in a digital world guarantees professional management of relevant records by preventing them from becoming obsolete. That said, how should we perform appraisal at the moment information is created, or even before the moment of creation?

\section{TOWARDS A DIFFERENT LEVEl OF APPRAISAL AND SELECTION}

In his book From Polders to Postmodernism. A Concise History of Archival Theory, John Ridener argues that "the lack of theoretical evaluation of key archival concepts can prove problematic in the long term. Without acute theoretical awareness, archivists who work exclusively and unquestioningly within any paradigm risk missing the opportunity to be innovative in exchange for inherited theory and practice"16. It is, however,

\footnotetext{
${ }^{15}$ Barbara Craig, Archival appraisal. Theory and practice (K.G. Saur Verlag 2004) 31-32.

${ }^{16}$ John Ridener, From Polders to Postmodernism. A Concise History of Archival Theory (Litwin Books 2009) 127-128.
} 
hard to appreciate the paradigms we are locked into. We should, however, at least take the incapability to find workable and practicable solutions for appraisal and selection seriously enough to question the existing paradigm.

Although appraisal and selection may be in crisis, the situation is far from hopeless. The Chinese use 危機 for crisis, which can also be understood as a possibility for positive change. Crisis creates opportunity. The profusion of attention given by the media, advisory boards, professionals and politicians to current problems in governmental information management is leading to a growing willingness to approach records management in a different way. Already in 1993, David Bearman and Margaret Hedstrom urgently called on archivists to change their approach to appraisal and selection under the slogan of "steering, not rowing" in order to cope with large volumes of (electronic) records ${ }^{17}$. Now, almost 20 years later, the time seems to be ripe not only to play a role at the operational and tactical level, but also the strategic level. The Dutch NationaalArchief [National Archives] is participating in three major initiatives that can be divided into the categories of strategic, instrumental and practical; these initiatives are geared towards contributing to the quality of information management. I will discuss the involvement of the National Archives in strategic and instrumental developments shortly.

\section{APPRAisAl AT THE STRATEgiC LEVEL}

The most important goal for the Dutch government is to get information management under control. In spite of the many standards in place, such as ISO 15489 with its guidelines on records management and baselines, in order to manage records in compliance with legal requirements, records managers, archivists and managers responsible for administrative processes realize that it is beyond the bounds of the possible to provide all information with the same high-quality care owing to resource limitations. There is a growing sense of urgency to make fundamental choices based on the answers given to two simple questions: What is the purpose of the created information? And which future needs must be met by this information? The answers to these questions determine to a large extent how information will be managed. There are some interesting examples of how agencies try to improve their mechanisms of control. The Dutch Ministry of Defence has begun to approach records management as risk management, defining risk as the product of the probability of an undesired situation and the impact of this situation at the moment it becomes reality. The Ministry has developed a risk analysis tool to identify the probability of an undesired situation as a result of insufficient records management. The impact of undesired situations are classified into three groups: high impact: loss or unauthorized alteration of information may cause serious casualties, large political problems or would paralyse military operations (e.g. military operations abroad, bomb disposal work); medium impact: loss or unauthorized alteration of information may result in lawsuits being lost and

\footnotetext{
${ }^{17}$ David Bearman and Margaret Hedstrom, Reinventing archives for electronic records. Alternative Service Delivery Options' in Margaret Hedstrom (ed), Electronic Records Management Programs Strategies (Archives \& Museum Informatics 1993) 89, 98.
} 
judgements requiring the payment of damages (e.g. performance of police tasks by the army, handling of complaints); low impact: loss or unauthorized alteration of information may cause some minor inconveniences (e.g. career counselling, training). In this so-called riskmanagement approach the impact level determines the records management efforts: the greater the impact, the less risk will be tolerated. The outcome of this procedure of appraising work processes in risk/impact categories with differentiated records management regimes also impacts the selection of records for transfer to a repository.

In this example, archivists and records managers are confronted with a different approach to appraisal, which is immediately linked to the primary processes in the organisation. It generates greater awareness among records managers and archivists that, in the past, appraisal and selection was organized as a one-dimensional, mainly cultural archival function. As a consequence, appraisal and selection decoupled from other informational functions. To put it more bluntly: records creators were not willing to invest a lot of time and money to bring their records in order many years after creation just to effect the smooth transfer of historically relevant records to the repositories of archival institutions. In the eyes of record creators, archivists did not contribute to the quality of records management, but were regarded as troublesome and demanding at a moment when the records no longer had much value for the agencies. For archivists, appraisal and selection might be the most important archival function, but that statement only makes sense when not only archivists and records managers but also those who are responsible for the processes (records creators) are convinced of the same, and receive at least some of the benefits from their efforts.

In their search to exert control over their information, governmental agencies are increasingly willing to take all informational aspects in consideration. The President of the Dutch National Audit Office, Saskia Stuyveling, has compared information to a flower ${ }^{18}$. The petals of the flower symbolize the different functions and different interests of information, records and archives: they support business processes, produce institutional memory, are tools for accountability and fact-finding, form a part of our heritage and historical memory. The petals, together with the heart (information), make a flower. When one petal is missing the result is an incomplete and mutilated flower. In fact, the same is the case with information. When one interest or function is missing or isolated, information management is imperfect and inadequate. The flower, with all its indispensable petals, in a way symbolizes the theory of the records continuum. No one interest is more important than another when speaking of information. Integrated information management results in attention being paid to the entire flower, not only to one or two petals.

Being in control, even in a digital world, is easier said than done. Being in control assumes a clear idea of the objectives in advance, which is difficult in many respects. To give but one example: it is still problematic to

${ }^{18}$ Saskia J. Stuiveling, 'Ready for take off' (January 2010). 
state whether a file is complete or not. No one is able to resolve this issue unless there is agreement in advance on the kind of information that should be in a file. This is not a matter to be solved solely by the records manager, but can only be executed in collaboration with officials responsible for functions and work processes. In this particular example responsible civil servants may analyse their work processes in order to identify the most important transactions and transmissions of information. The next step can be to value and determine which documents should be in the file to be able to label it as 'complete'. A good illustration of the aforementioned within this framework are the attempts of the scientific bureau of the Counsel for Prosecution in the Netherlands to define what kind of information should be in a court file to determine whether the file is complete. When this kind of clarity is achieved, it will also have a positive impact on the rights of citizens who want to know how government agencies operate. At least they will know what kind of documents should be in a file.

The Dutch NationaalArchief and ministries are working together on some pilot projects to redefine information management in a digital environment. I want to stress the importance of the human factor of working together in the processes of establishing control of information management. We must get accustomed to the idea that information management is an ongoing task that never will be complete. The first thing we did in these pilot projects was to redefine and broaden the scope of appraisal. As shown in some of the examples mentioned above, appraisal is a broader function than just assigning a value for purposes of defining whether a record should be kept or destroyed. All kinds of information issues have aspects of appraisal: whether to declare the completeness of a file, providing public access to information, destroying or obliterating information because of privacy reasons or assigning values to records for purposes of making selection decisions - everything is all about appraisal. In these pilot projects, all issues associated with information are examined and treated in concert with other archival and informational functions.

The most important thing in these pilots is to reorganize responsibilities with regard to information management. The existing trilateral consultation involved in preparing selection and retention lists will be upgraded to a new permanent trilateral body within every ministry. These bodies will assume responsibility for all aspects of information management within a given ministry. They consist of a representative of the ministry (records creator), preferably at the level of Chief Information Officer, the state archivist, and an independent specialist in matters of public accountability.

The NationaalArchief has launched a pilot with some ministries to test the effectiveness of this new body on the quality of information management. This new body's agenda will contain all issues related to information. Of course, the permanent trilateral body also has to deal with issues of appraisal for selection, and it has at its disposal three newlydesigned - but still experimental - instruments for making decisions about which kind of information should be kept for what period, destroyed or transferred to the digital repository of the National Archives. These instruments are named system analysis, risk analysis and trend analysis, and are designed to make accountable appraisal and selection decisions in a 
digital information society. Not years after information is created, but immediately when it is born and is of relevance for the creating agency.

\section{APPRAISAL ON AN INSTRUMENTAL LEVEL: A TOOLKIT}

In collaboration with a number of departments, the Nationaal Archief has developed a coherent methodology using the building blocks for appraisal and selection methodology as developed by an advisory board ${ }^{19}$. Within this framework, three appraisal tools are being developed: system analysis, trends analysis and risk analysis. These tools have been applied in the recent past in various pilot trials, and where necessary adjusted and refined on the basis of their results.

These three tools complement each other, and identify the information that is relevant to retain and which give substance to the selection objectives. In 2007, the Commission on Appraisal and Selection instituted by the then-chief state archivist general formulated a new and integrated selection objective, which was accepted in December 2010 by the Minister. The objective is as follows:

"The purpose of appraising, selecting and acquiring archives is to bring together and secure the sources that enable individuals, organisations and social groups or bodies to discover their histories and to reconstruct the past of state and society (and their interaction). To this end, those archives or parts of archives which must be secured are: a. representative of those things which have been recorded in society; $b$. representative of the activities of the members (people and organisations) of society; c. considered by commentators of significance, exceptional or unique because these reflect the significant, exceptional and unique social developments, people and organisations of a particular period" 20 .

Application of this suite of tools will lead to identification of the information that will make it possible to reconstruct the history of the state and society (and their interaction).

\section{a) System Analysis}

A system analysis will help every records-creating agency to determine where relevant information converges in an organisation to reconstruct the core activities of the agency. The information that is gathered at these information hubs will be assigned for perpetual retention, and will be managed from the time of its creation.

The system analysis maps out the structures (the relationships between players, functions and information objects) at the level of one of the players in order to identify essential information required for the

\footnotetext{
${ }^{19}$ K.J.P.F.M. Jeurgens, A.C.V.M. Bongenaar and M.C. Windhorst, Gewaardeerd Verleden. Bouwstenen voor een nieuwe waarderingsmethodiek (Nationaal Archief 2007); Robbert Jan Hageman, Charles Jeurgens and Ruud Yap, 'A new approach to appraisal: Building blocks for a new appraisal method for archives' [2010] COMMA 125-132.

${ }^{20}$ See Jeurgens, Bongenaar and Windhorst (n 19) 37-38.
} 
reconstruction of the activities of an organisation ${ }^{21}$. The system analysis consists of two distinct components: an institutional component and a component of substance:

a. Institutional: information hubs will be designated on the basis of an analysis of the agency's structures for decision-making and communication. These information hubs will be the most critical links in the processes of decision-making, communications and implementation as well as in the records created in these hubs, which will be eligible for continuing retention.

b. Substance: every government organisation has a core assignment as its substance. The substantive part of this analysis identifies which information is of the utmost essence in the implementation of the objectives of the organisation in question.

The big advantage of applying this tool is that the relevant documents can already be selected at the time of their creation.

\section{b) Risks Analysis}

From the perspective of a records-creating agency, risk analysis is intended to identify the information that is of vital importance to the organisation in question and that is required to manage the chief risk in the accomplishment of all tasks in the area of information provision. The instrument developed by the Ministry of Defence may serve as an example.

This instrument uses a questionnaire to understand the issue of which political, judicial, financial, social and societal risks would be incurred if particular information were not accessible. The priority of information management lies where the risks are greatest. At the heart of risk assessment is the need to make choices when resources are inadequate for achieving equal levels of accessibility and management.

\section{c) Trends Analysis}

Trends analysis is complementary to system analysis. Trends analysis aims to identify the information in the layer above the substrate of essential basic data that documents distinctive developments in society.

This analysis follows a stepped structure. Planning offices ${ }^{22}$ carry out periodic analyses across society in which characteristic developments, trends and deviations are mapped out. This serves as the basis for the players (record-creating agencies and non-governmental organisations) which had a dominant role within these developments to be identified. Finally, the outcomes of the trends analyses are translated into processes and transferred to the players' activities and subjects, which have engaged them so that it can be determined what of their information will be retained.

\footnotetext{
${ }^{21}$ Although the system analysis can be applied at several levels, the National Archive will for the time being apply this at the level of the individual records-creating agencies or departmental record officers.

22 The Social and Cultural Planning Office is currently carrying out a social trends analysis for the period from 2005 up to the present day $(=2010)$ and resulted in a report Vic Veldheer and Rob Bijl, Actuele maatschappelijke ontwikkelingen 2010. Een bijdrage aan het waarderen en selecteren van informatie ten behoeve van toekomstige archieven (SCP 2011).
} 


\section{CONCLUDING REMARKS}

There is no reason at all to think that appraisal and selection are outdated functions in the world of digital information management. The opposite is in fact true: appraisal and selection are indispensable for managing and controlling the flood of information within the realm of government organisations. Appraisal is, however, a more allencompassing function than it used to be in the past, when it was solely connected to the selection of records. Only when appraisal and selection are fully integrated in information and records-management processes will it be possible to make a contribution to the quality of information. Appraisal and selection needs to move from a rear-end to a front-end function in order to be effective. In the first place, a decision must be made as to which information should be kept in a proper records management system, and the required metadata should be added. Linking information to actual work processes is of vital importance. Only then can transparent, deliberate and entirely appraisal-based decisions be made that are the result of assessment of all interests (operational management, legal requirements, accountability, history and heritage). Less is more. The example of the Ministry of Defence shows this clearly. Of course, there are risks in this form of appraisal, but maintaining the status quo without proper management is as risky if not riskier.

The NationaalArchief in the Netherlands is involved in improving the quality of information management of governmental agencies. This takes place on different levels. One of the important improvements is the recognition that information is a strategic asset that deserves attention on a strategic organisational level in order to make transparent decisions. Transparency means that it should be clear to everyone how decisions are made and why some information is destroyed while other information is still available. Accountability is the most important imperative in appraisal and selection. The pilot projects to improve decision-making on information management on the strategic level are promising. The instruments, which are developed to make transparent selection decisions at a very early stage of records creation, will hopefully contribute to reliable and well-founded records management in a digital era in which the rights of citizens play a leading role as one of the important interests that have to be taken into account. 